Archiv für Mikrobiologie 40, 370-382 (1961)

From the Plant Nutrition Laboratory, The University of Michigan, Ann Arbor, Michigan, U.S.A. Paper No. 33.

\title{
Factors Limiting Microbial Activities in Soil
}

\section{The Effect of Sulfur}

\author{
By \\ G. Stotzky and A. G. Norman \\ With 5 Figures in the Text \\ (Received April 13, 1961)
}

Previous investigations in this laboratory have shown that the addition of nitrogen and phosphorus was necessary for the rapid decomposition of glucose added to a sandy soil, but that the level of some other nutrient element or elements was still limiting maximum microbial activity. The purpose of the present investigation was to determine which inorganic elements other than nitrogen and phosphorus were required for maximum rate of glucose oxidation in this soil.

\section{Experimental}

The soil used in these studies was classified as an Ottawa loamy fine sand. Its chemical and physical properties, as well as the methods of preparation and incubation, were described previously (STотzку and Noruar 1961). All experiments, unless otherwise noted, were conducted with $200 \mathrm{~g}$ samples of soil in $1 / 2$ pint widemouth canning jars. The samples received $0.08 \%(\mathrm{w} / \mathrm{w})$ nitrogen as $\mathrm{NH}_{4} \mathrm{NO}_{3}$ and $0.04 \%(\mathrm{w} / \mathrm{w})$ phosphorus as $\mathrm{K}_{2} \mathrm{HPO}_{4}$ and $\mathrm{KH}_{2} \mathrm{PO}_{4}$ combined to give a $\mathrm{pH}_{\mathrm{H}}$ of 6.95 . Glucose, nitrogen, phosphorus, and other elements were added with sufficient water to bring the soil moisture content to field capacity $(16 \% \mathrm{w} / \mathrm{w})$. The soils were incubated at $25 \pm 1^{\circ} \mathrm{C}$ and continuously flushed with $\mathrm{CO}_{2}$-free air. The $\mathrm{CO}_{2}$ evolved from the soils was collected in NaOH and determined titrimetrically (STorzar et al. 1958).

\section{Results \\ Effect of elements other than nitrogen and phosphorus on the rate of $\mathrm{CO}_{2}$ evolution}

In order to determine if mineral elements other than nitrogen and phosphorus were required for maximum microbial activity, a mineral nutrient solution was added at various concentrations with $4 \%(\mathrm{w} / \mathrm{w})$ glucose. This high level of glucose was used in order to maximize any effects of the minerals. The composition of the complete mineral solution at different concentrations, referred to as "relative concentrations", is presented in Table 1. Deficient solutions, i.e., solutions containing all elements except one, were added at a relative concentration of 10 ; all 
amendments were adjusted to $p_{H} 7$ before addition to the soil. The influence of complete and deficient mineral solutions on the rate of $\mathrm{CO}_{2}$ evolution is presented in Fig.1 a. The addition of complete solution increased the rate of $\mathrm{CO}_{2}$ evolution during the early part of the incubation. The rate of respiration was greater in the soils treated with the higher concentrations, but no additional increase was observed with relative concentrations greater than 10; only a slight additional increase was noted with concentrations greater than 5 .

Table 1. Composition of mineral solution at different relative concentrations (mg/100 g soil)

\begin{tabular}{|c|c|c|c|c|c|}
\hline \multirow{2}{*}{ Element } & \multicolumn{5}{|c|}{ Relative concentration } \\
\hline & 1 & 5 & 10 & 20 & 30 \\
\hline $\mathrm{N}$ & 1.05 & 5.25 & 10.50 & 21.00 & 31.50 \\
\hline $\mathrm{P}$ & 0.154 & 0.77 & 1.54 & 3.08 & 4.62 \\
\hline $\mathrm{K}$ & 1.17 & 5.85 & 11.70 & 23.40 & 35.10 \\
\hline $\mathrm{Ca}$ & 1.00 & 5.00 & 10.00 & 20.00 & 30.00 \\
\hline $\mathrm{Mg}$ & 0.24 & 1.20 & 2.40 & 4.80 & 7.20 \\
\hline S & 0.32 & 1.60 & 3.20 & 6.40 & 9.60 \\
\hline $\mathrm{Fe}^{\mathrm{I}}$ & 0.0025 & 0.0125 & 0.025 & 0.050 & 0.075 \\
\hline $\mathrm{Mn}$ & 0.0025 & 0.0125 & 0.025 & 0.050 & 0.075 \\
\hline B & 0.0025 & 0.0125 & 0.025 & 0.050 & 0.075 \\
\hline Zn & 0.00025 & 0.00125 & 0.0025 & 0.005 & 0.0075 \\
\hline Mo & 0.00025 & 0.00125 & 0.0025 & 0.005 & 0.0075 \\
\hline $\mathrm{Cu}$ & 0.0001 & 0.0005 & 0.001 & 0.002 & 0.003 \\
\hline Cl & 1.77 & 8.85 & 17.70 & 35.40 & 53.10 \\
\hline $\mathrm{Na}^{2}$ & 0.13 & 0.65 & 1.30 & 2.60 & 3.90 \\
\hline $\mathrm{C}^{1}$ & 0.006 & 0.03 & 0.06 & 0.12 & 0.18 \\
\hline
\end{tabular}

The soil treated with a relative concentration of 30 evolved slightly less $\mathrm{CO}_{2}$ at the peak of respiration (3rd day) than did the soil which received a concentration of 20 . There was also an inverse relationship between respiration and relative concentrations of minerals greater than 1 on the second day of incubation. This suppression in microbial activity at high levels of glucose and inorganic salts was also observed in the previous study (STOTzkr and Norman 1961) and was probably the result of increased osmotic pressures.

The rate of $\mathrm{CO}_{\mathrm{g}}$ evolution from soils treated with the various deficient solutions was the same as from the soil treated with complete solution at a relative concentration of 10 , with the exception of the sample which received the solution containing no sulfur. This soil respired at a rate similar to the one which received only nitrogen and phosphorus, indicating that sulfur was responsible for the increased respiration of the samples treated with complete mineral solutions. 
Once the maximum rate of respiration was attained, the level of $\mathrm{CO}_{2}$ evolution decreased rapidly in the soils which had received sulfur, presumably as a result of substrate depletion. The soils which received no sulfur evolved less $\mathrm{CO}_{2}$ at the time of maximum respiration, but maintained a higher level of evolution later in the incubation period. Inasmuch as the endogenous organic matter content of this soil was low and previous
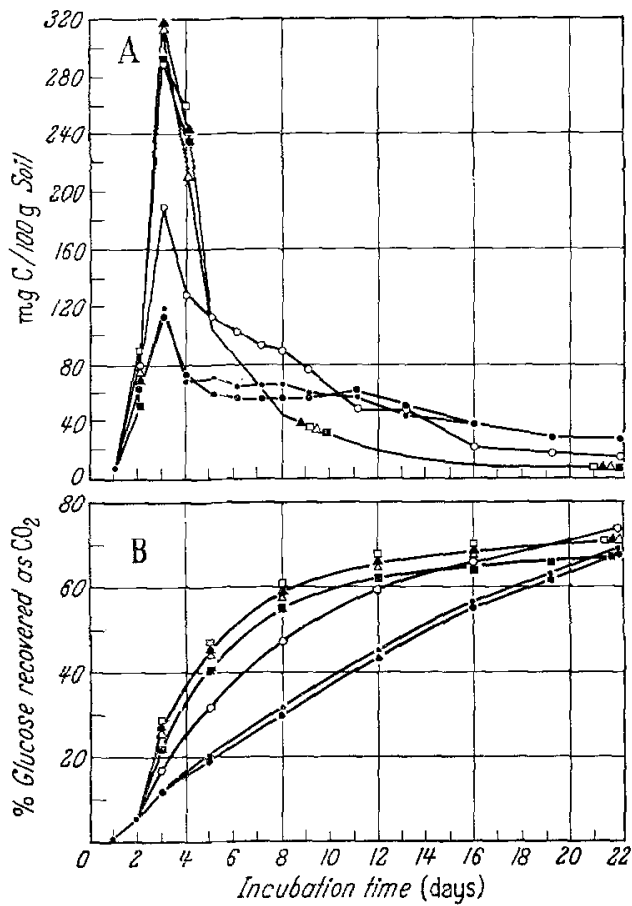

Fig. 1. Effect of concentration of complete and deficient mineral solutions on microbial activity in a soil treated with $4^{0} \%$ glucose. A. Daily rate of $\mathrm{CO}_{2}$ evolution. B. Cumulative recovery of added glucose as $\mathrm{CO}_{2}$. Relative concentration of mineral solution: None; $01 ; \square 5 ; \Delta 10$ (complete + deficient); $20 ; 30 ; \bullet 10$ (S-deficient) experiments (STOTzKx and NorMAN 1961) had suggested that no appreciable "priming action" occurred, it was assumed that all evolved $\mathrm{CO}_{2}$ was derived from the added glucose. After 8 days of incubation, $\mathrm{CO}_{2}$ equivalent to approximately $60 \%$ of the added glucose was evolved from soils

Table 2. $p_{H}$ of soils treated with different concentrations of mineral solution and $4 \%$ glucose

( $\mathrm{p}_{\text {H }}$ determined after 22 days of incubation)

\begin{tabular}{c|c}
\hline $\begin{array}{c}\text { Relative concentration } \\
\text { of mineral solution }\end{array}$ & $p \mathrm{r}$ \\
\hline No minerals added & 6.5 \\
1 & 7.4 \\
5 & 8.3 \\
10 & 8.5 \\
20 & 8.5 \\
30 & 8.3 \\
10 & 8.4 \\
(Deficient solutions) $^{1}$ & \\
10 & 6.3 \\
(S-deficient solution) &
\end{tabular}

1 All deficient solutions except the S-deficient solution.

treated with sulfur, and only an additional 10\% was recovered in the following 14 days (Fig.1 b). The recovery of glucose from soils which received no sulfur was essentially linear throughout the entire incubation period. Nevertheless, the quantity of carbon recovered as $\mathrm{CO}_{2}$ at the end of the incubation was approximately the same for all treatments. The addition of sulfur, therefore, resulted only in a more rapid but not in a greater total decomposition of glucose. These results were similar to those obtained in the nitrogen and phosphorus addition experiments (STотZKY and NoRMAN 1961), and support the suggestion that, although the original 
concentration of inorganic nutrients determines the rate of glucose utilization, the degree of utilization is controlled by the turnover rate of these nutrients.

The $p_{\mathrm{H}}$ of the soils was determined potentiometrically at the end of the incubation on a 1:2 soil: water mixture (Table 2). The $\mathrm{p}_{\mathrm{H}}$ was correlated with the rate of $\mathrm{CO}_{2}$ evolution: the soils which received minerals at a relative concentration of 5 or greater and from which $60 \%$ of the glucose had been recovered after 8 days had a $p_{H}$ higher than 8 ; the soils which received no sulfur and in which oxidation of the glucose proceeded at a linear rate had a final $\mathrm{p}_{\mathrm{H}}$ approximately the same as at the beginning of the incubation; and the soil which received complete mineral solution at a relative concentration of 1 exhibited a rate of respiration and a final $\mathrm{p}_{\mathrm{H}}$ intermediate between the above mentioned two groups of soil. The soils in which decomposition proceeded at a rapid rate were densely overgrown with fungi, whereas visible fungal growth was sparse in the soils which received no sulfur. These relationships between, rate of microbial activity, visible overgrowth of fungi, and $\mathrm{p}_{\mathrm{E}}$ were also observed in the
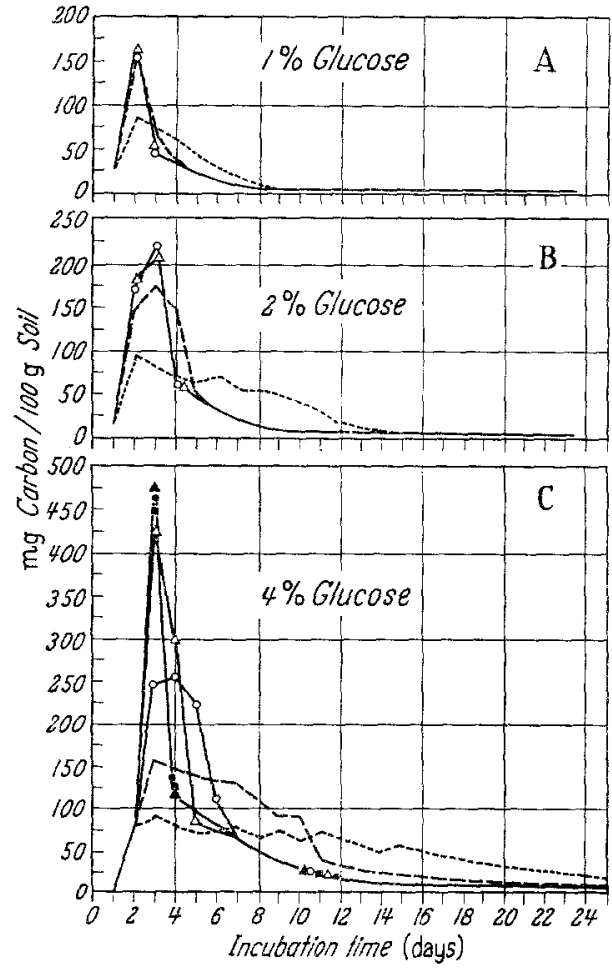

Fig. 2. Effect of concentration of sulfur added as $\mathrm{MgSO}$, on the daily rate of $\mathrm{CO}_{2}$ evolution from a soil treated with various levels of glucose. Per cent sulfur: ....... None;.... $.3 .2 \cdot 10^{-4} ; \circ 8.0 \cdot 10^{-4} ; \Delta 1.6 \cdot 10^{-3}$. $\bullet 3.2 \cdot 10^{-3} ;$ a $6.4 \cdot 10^{-3} ; 11.3 \cdot 10^{-2}$ previous study. Although the total amount of glucose oxidation during the incubation period was essentially the same for all treatments, the size of the microbial population and possibly also the pathways and organisms involved in the oxidation were apparently influenced by the levels of available nitrogen, phosphorus, and sulfur.

The results of this experiment indicated that sulfur was limiting maximum microbial activity in this soil and that the small amount of sulfur initially present in the soil was alternately mineralized and reutilized by the microorganisms. The effect of various ratios of sulfur and 
glucose on the rate of respiration was examined, in order to further verify these observations.

Effect of various levels of sulfur and glucose on the rate of $\mathrm{CO}_{2}$ evolution

The $\mathrm{CO}_{2}$ evolution curves for soils treated with 1,2 , or $4 \%$ glucose and with different levels of sulfur as $\mathrm{MgSO}_{4}$ showed that the requirement for sulfur increased as the concentration of glucose increased (Fig.2). A sulfur concentration of $3.2 \cdot 10^{-4} \%$ was sufficient to obtain a maximum

Table 3. Effect of carbon: sulfur ratios on rate of respiration

\begin{tabular}{|c|c|c|c|c|c|}
\hline \multicolumn{3}{|c|}{ Additives } & \multirow{2}{*}{$\mathrm{C} / \mathrm{S}$ of additives } & \multirow{2}{*}{$\begin{array}{c}\mathrm{C} / \mathrm{S} \text { of soil } \\
\text { and additives }\end{array}$} & \multirow{2}{*}{$\begin{array}{l}\text { Relative rate } \\
\text { of respiration }\end{array}$} \\
\hline $\begin{array}{c}\text { Glucose } \\
(1 / 0)\end{array}$ & $\begin{array}{c}\text { Carbon } \\
(\mathrm{g} / 100 \mathrm{~g})\end{array}$ & $\begin{array}{c}\text { Sulfur } \\
(\mathrm{g} / 100 \mathrm{~g})\end{array}$ & & & \\
\hline 0 & 0 & 0 & 0 & 421 & \\
\hline 1 & 0.4 & 0 & $\infty$ & 1474 & 1 \\
\hline 1 & 0.4 & $3.2 \cdot 10^{-4}$ & 1250 & 800 & 4 \\
\hline 1 & 0.4 & $8.0 \cdot 10^{-4}$ & 500 & 475 & 4 \\
\hline 1 & 0.4 & $1.6 \cdot 10^{-3}$ & 250 & 283 & 4 \\
\hline 2 & 0.8 & 0 & $\infty$ & 2526 & 1 \\
\hline 2 & 0.8 & $3.2 \cdot 10^{-4}$ & 2500 & 1371 & 3 \\
\hline 2 & 0.8 & $8.0 \cdot 10^{-4}$ & 1000 & 814 & 4 \\
\hline 2 & 0.8 & $1.6 \cdot 10^{-3}$ & 500 & 485 & 4 \\
\hline 4 & 1.6 & 0 & $\infty$ & 4632 & 1 \\
\hline 4 & 1.6 & $3.2 \cdot 10^{-4}$ & 5000 & 2514 & 2 \\
\hline 4 & 1.6 & $8.0 \cdot 10^{-4}$ & 2000 & 1492 & 3 \\
\hline 4 & 1.6 & $1.6 \cdot 10^{-3}$ & 1000 & 889 & 4 \\
\hline 4 & 1.6 & $3.2 \cdot 10^{-3}$ & 500 & 492 & 4 \\
\hline 4 & 1.6 & $6.4 \cdot 10^{-3}$ & 250 & 260 & 4 \\
\hline 4 & 1.6 & $1.3 \cdot 10^{-2}$ & 125 & 132 & 4 \\
\hline
\end{tabular}

1 Soil contained $0.16 \%$ carbon and $3.8 \cdot 10^{-4} \%$ sulfur.

${ }^{2}$ Arbitrary scale increasing from 1 to 4 .

rate of $\mathrm{CO}_{2}$ evolution from soil treated with $1 \%$ glucose (Fig. 2a). When the glucose concentration was doubled, an addition of $8.0 \cdot 10^{-4} \%$ sulfur resulted in the maximum rate of respiration (Fig. $2 \mathrm{~b}$ ). An increase in the ghucose level to $4 \%$ required a sulfur concentration of at least $1.6 \cdot 10^{-3} \%$ for maximum rate of $\mathrm{CO}_{2}$ evolution (Fig. $2 \mathrm{c}$ ). Increases in respiration with levels of sulfur greater than $1.6 \cdot 10^{-3} \%$ were slight, and after 4 days of incubation the total amount of $\mathrm{CO}_{2}$ evolved from samples treated with $4 \%$ glucose and levels of sulfur greater than $8.0 \cdot 10^{-4} \%$ was identical.

At the termination of the incubation, the per cent of glucose recovered as $\mathrm{CO}_{2}$ at each level of glucose addition was approximately the same for all concentrations of sulfur. A carbon: sulfur ratio of about 900 or less was required for the maximum rate of respiration in this soil, regardless of the levels of glucose and sulfur added (Table 3 ). The difference between 
the maximum rates of $\mathrm{CO}_{2}$ evolution attained in this (Fig. $2 \mathrm{c}$ ) and the previous (Fig. $1 \mathrm{a}$ ) experiments ( $477 \mathrm{vs} .318 \mathrm{mg} \mathrm{C} / 100 \mathrm{~g}$ soil $/ 24 \mathrm{hr}$.) from samples treated with $4 \%$ glucose and sulfur was probably the result of the higher osmotic pressures developed when mineral solutions rather than $\mathrm{MgSO}_{4}$ were added.

The enhancement of microbial activity due to the addition of sulfur was further observed when the recovery of unchanged glucose and the

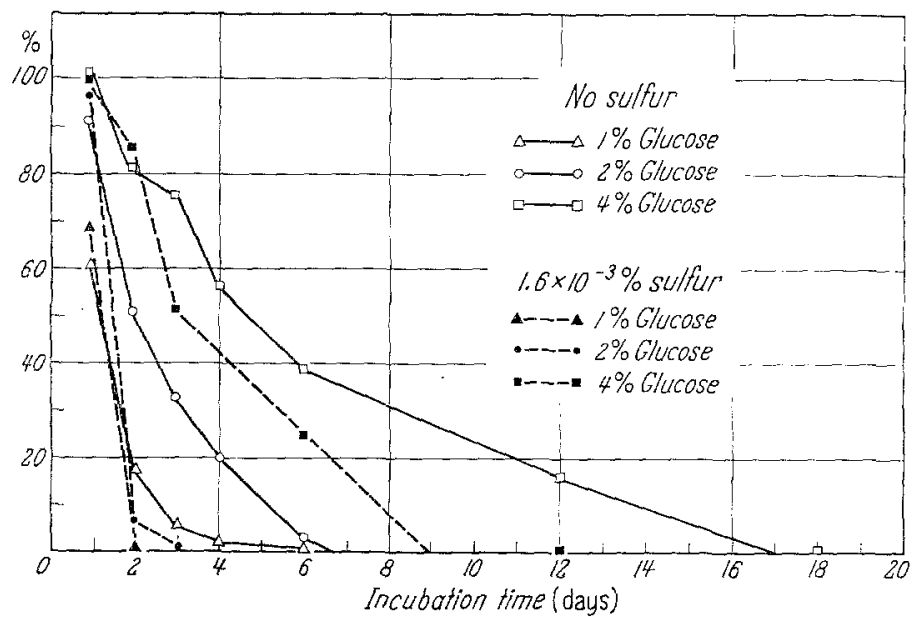

Fig. 3. Effect of sulfur on the percent recovery of unchanged glucose after various periods of incubation from a soil initially treated with 1,2 , or $4 \%$ glucose

soil $\mathrm{p}_{\text {H }}$ were measured after various lengths of incubation. Multiple $100 \mathrm{~g}$ subsamples of soil treated with $0.08 \%$ nitrogen, $0.04 \%$ phosphorus, $1.6 \cdot 10^{-3} \%$ sulfur (as $\mathrm{MgSO}_{4}$ ), and 1, 2, or $4 \%$ glucose were established (STотzKY et al. 1958). Because the previous experiment indicated that $1.6 \cdot 10^{-3} \%$ sulfur resulted in the maximum rate of respiration with all 3 levels of glucose, this concentration was used in subsequent experiments. Sub-samples of soil were withdrawn periodically during the incubation period, extracted with water, and glucose was determined enzymatically (Sтотzky and NoRman 1961). The disappearance of glucose from the soil was more rapid in the presence of sulfur than in its absence. The rate of glucose disappearance, both in the presence and absence of sulfur, was dependent upon the original concentration of glucose (Fig. 3).

The $p_{H}$ throughout the incubation was lower in the soils which received no sulfur (Fig.4), probably due to the accumulation of acidic metabolic intermediates (STotzky and Norman 1961). The decomposition of both glucose and intermediates was accelerated by the addition of sulfur. Although the final $p_{\text {H }}$ of the soils was directly related to the amount of glucose added, as in the previous studies, it was higher for 
each level of glucose when sulfur was added, indicating a greater production and/or accumulation of basic material when the supply of all necessary nutrient elements was ample.

These results clearly show that there was a direct relationship in this soil between microbial activity and the relative levels of glucose and sulfur. Inasmuch as sulfur was added as the sulfate-ion and oxygen was

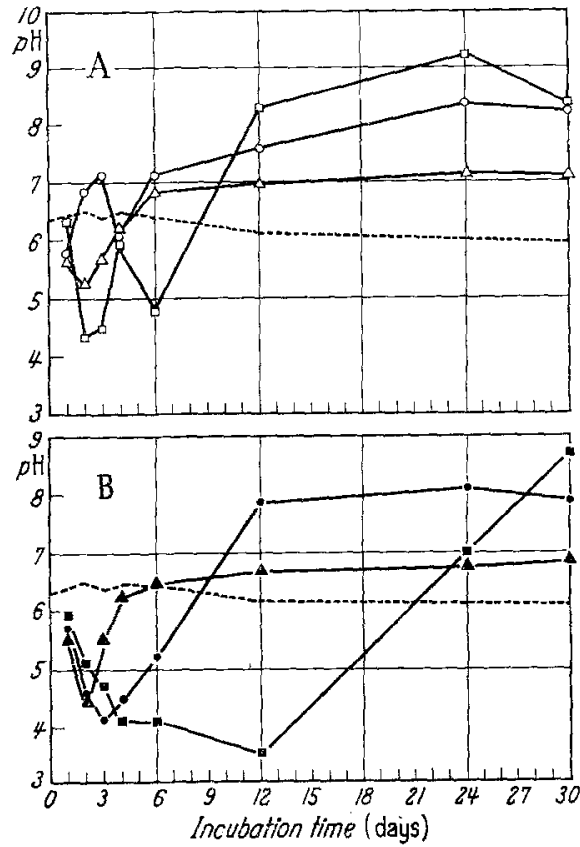

Fig.4. Effect of sulfur and glucose on the soil pre during incubation. A $1.6 \cdot 10^{-3} \%$ Sulfur: ..... No Glucose; $\Delta 1 . \%$ Glucose; $02 \%$ Glucose; [ 4\% Glucose. B No Sulfur: - . . . . No Glucose; $11 \%$ Glucose; $\bullet 2 \%$ Glucose; $4 \%$ Glucose found to be limiting during periods of active oxidation of the glucose (SToTzky 1960; STotzky and Norman 1961), it was possible that the requirement was not for sulfur as an element but for sulfate as an electron acceptor. In order to clarify this possibility, compounds containing sulfur at different oxidation stages and in various structural configurations were tested for their ability to satisfy the sulfur requirement.

\section{Effect of type of sulfur compound on the rate of $\mathrm{CO}_{2}$ evolution}

Various sulfur compounds, in amounts designed to give a final concentration of $1.6 \cdot 10^{-3} \%$ sulfur, were added to soils containing $4 \%$ giucose, $0.08 \%$ nitrogen, and $0.04 \%$ phosphorus. The compounds were representative of those present in soil (STARKEY 1950) and included some which could not act directly as electron acceptors: sulfate as

$\mathrm{MgSO}_{4}$; thiosulfate as $\mathrm{Na}_{2} \mathrm{~S}_{2} \mathrm{O}_{3}$; carbamide as thiourea; sulfide as 1-cysteine hydrochloride, glutathione, and thioglycolic acid; disulfide as l-cystine; thioether as dl-methionine; the thiazole ring as thiamine hydrochloride; and elemental sulfur (sublimed). It was assumed that the carbon and nitrogen contained in the organic sulfur compounds did not contribute appreciably to the rate or amount of $\mathrm{CO}_{2}$ evolution, inasmuch as the quantities added did not exceed $12 \mathrm{mg}$ or $5.6 \mathrm{mg}$, respectively. This assumption was verified by HESSE (1957), who found that $25 \mathrm{mg}$ of carbon added as methionine or cystine to $100 \mathrm{~g}$ of East African soil was completely oxidized in less than 10 days. All the compounds, except elemental sulfur and thiourea, readily satisfied the requirement for sulfur 
(Fig.5). This was in agreement with studies of FREDERICK et al. (1957), Jordar and Barker (1959), Starkey (1950) and Steinberg (1941), which have indicated that most organic forms of sulfur are as available as sulfate to most soil microorganisms. A slight lag in $\mathrm{CO}_{2}$ evolution was observed with cystine, thiamine, and thioglycolate. The amount of glucose recovered as $\mathrm{CO}_{2}$ at the end of the experiment was the same for all treatments, again showing that available sulfur only increased the rate but not the total amount of glucose decomposition.

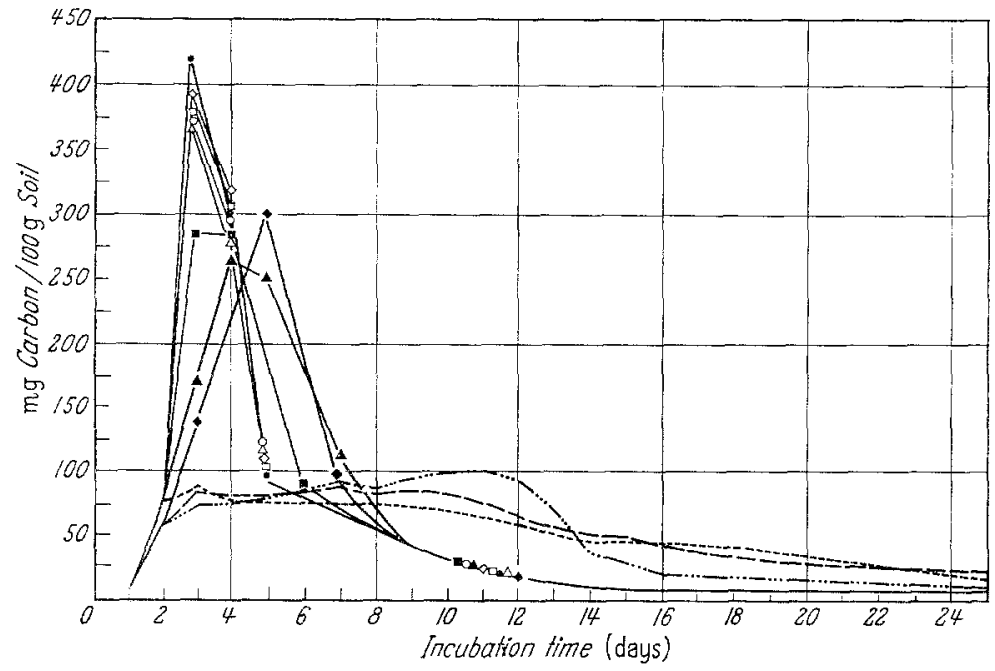

Fig. 5. Effect of type of sulfur compound on the daily rate of $\mathrm{CO}_{2}$ evolution from a soil treated with $4 \%$ glucose. $\cdots \cdots$ No Sulfur; $\cdots$..... Thiourea; - - Elemental Sulfur; $\bullet \mathrm{MgSO}_{4} ; \square \mathrm{Na}_{2} \mathrm{~S}_{2} \mathrm{O}_{3}$ $\Delta$ Cysteine; Cystine; $\diamond$ Methionine; Thioglycolic Acid; $\circ$ Glutathione; $\uparrow$ Thiamine

The increased rate of $\mathrm{CO}_{2}$ evolution from soils treated with $\mathrm{MgSO}_{4}$, therefore, was apparently the result of sulfur as a nutrient and not of sulfate acting as an electron acceptor. The addition of the nitrate ion as a possible electron acceptor also did not affect the rate of respiration of this soil (unpublished data).

\section{Discussion}

All the forms of sulfur tested, except elemental sulfur and thiourea, readily served as a source of sulfur. Elemental sulfur was utilized only slightly, suggesting the absence of bacteria of the genus Thiobacillus. Many heterotrophic microorganisms, however, are capable of oxidizing elemental sulfur in the presence of decomposable organic matter, though at a rate slower than the Thiobacilli (GLEEN and QUASTEL 1953; Guittonneav and Kemling 1932; Thomas and Hendricks 1943). The possible absence of Thiobacilli, therefore, would not explain the negligible utilization. The elemental sulfur used in these studies was 
insoluble in water and was added as a suspension. VoGLER and UMBREIT (1941) suggested that direct contact between sulfur particles and bacterial cells is required for oxidation of elemental sulfur. Although subsequent studies of GLEen and QuASTEL (1953), STARKEY et al. (1956) and VISHNIad and Sarter (1957) have indicated that direct contact is not necessary, the soils in this study were incubated under static conditions and the opportunity for direct contact existed. Nevertheless, the insolubility and the small quantity of elemental sulfur added (1.6 mg/100 $\mathrm{g}$ soil) undoubtedly resulted in poor distribution of the particles throughout the soil and in limited opportunity for contact with the microorganisms.

Thiourea is known to be toxic, even at low concentrations, to certain microorganisms. FuLLER et al (1950) found that $20 \mathrm{mg}$ thiourea $/ 100 \mathrm{~g}$ soil inhibited nitrification but not ammonification in an alkaline soil; at a concentration of $10 \mathrm{mg} / 100 \mathrm{~g}$, thiourea was slowly nitrified. QUASTEL and SCHOLE FIELD (1951) observed that $25 \mathrm{mg}$ thiourea/l. prevented nitrification in pure culture and that adaptation of the nitrifiers to this compound did not occur. FREDERICK et al. (1957) reported that $1 \%$ thiourea was only slowly decomposed in soil and that, during a 42-week incubation period, it caused $99 \%$ reduction in the number of fungi and greatly reduced the numbers of bacteria and actinomycetes. This compound was also a poor source of sulfur for Aspergillus niger (STEINBERG 1941). Although the rate of $\mathrm{CO}_{2}$ evolution from the thioureatreated soil ( $3.8 \mathrm{mg}$ thiourea/100 $\mathrm{g}$ soil) was only slightly greater than that from soil which received no sulfur, thiourea apparently was not toxic, otherwise no glucose oxidation would have occurred. The nontoxicity of thiourea and the negligible availability of its sulfur suggested that this compound was decomposed slowly in this soil.

The lag in the rate of respiration from soils treated with thiamine and thioglycolic acid was in agreement with the results of other investigators, and was probably a reflection of the time required for the development of specific populations capable of decomposing these compounds. FREDERTCK et al. (1957) observed that thiamine was decomposed in soil at a slower rate than methionine or cystine. STEINBERG (1941) reported that $A$. niger was unable to utilize thiamine or thioglycolate as a source of sulfur. The latter compound did not replace cysteine in the culture of rhizosphere bacteria (WEST and LocHHEAD 1940).

A lag in the rate of respiration occurred also when cystine was added. The greater availability of cysteine as compared to cystine was not in agreement with the suggestion of FRENeY (1958) that the pathway of cysteine decomposition in soil is cysteine $\rightarrow$ cystine $\rightarrow$ sulfate. This pathway was also proposed by STAHL et al. (1949) for the oxidation of 
cysteine by Microsporum gypseum. Methionine was also utilized more rapidly as a source of sulfur than was cystine, in contradiction to reports by Frederick et al. (1957), QUASTeL and Scholefield (1951) and STARKEY (1950) that methionine is less susceptible than cystine to decomposition.

It has been reported that methionine or its decomposition products inhibit nitrification and microbial growth (HESSE 1957; LeES 1952; QUASTEL and ScholeField 1951; STAHL et al. 1949). STARKEY and co-workers $(1956,1957)$ found that, as a result of microbial decomposition, the sulfur of methionine was lost from soil as volatile thiol and disulfide. No odor of volatile sulfur compounds was detected during the course of these experiments, and the rate of respiration with methionine was similar to that obtained with $\mathrm{MgSO}_{4}$. The level of methionine added in this study $(7.5 \mathrm{mg} / 100 \mathrm{~g}$ soil), however, was only $5 \%$ of the concentration reported by QUASTEL and SCHOLEFIELD (1951) to be inhibitory for nitrification.

The differential utilization in this study of sulfur compounds of various complexity, e.g., glutathione vs. thioglycolate, agreed with the suggestion of STARKEY (1950) that the decomposability of sulfur in soils is not entirely related to the type of sulfur linkage but to the other portions of the molecule as well.

The sulfur of methionine, as well as that of the other compounds, was apparently incorporated rapidly into microbial cells. The addition of sulfur compounds to soil is usually accompanied by a marked decrease in $p_{H}$ as a result of the formation and accumulation of sulfate (FREDERroK et al. 1957; STARKEY 1956; WAKSHAN 1952). In this study, the $p_{H}$ of soils which received no sulfur was lower throughout the incubation period than the $\mathrm{p}_{\mathrm{H}}$ of samples treated with $\mathrm{MgSO}_{4}$. The non-toxicity of the sulfur compounds; the absence of volatile sulfur products of methionine decomposition; the equal total utilization of glucose in both the presence and absence of sulfur; the lack of increased respiration with levels of sulfur greater than amounts required for maximum rates of respiration; and the failure of sulfur additions to lower the $p_{H}$ of the soil, all indicated that the sulfur economy in the soil was well balanced, that no free sulfate accumulated in the presence of available substrate, and that there was a rapid mineralization and re-utilization of the small amount of sulfur originally present in the soil. These results were in agreement with those of the previous study, which showed that the small amounts of soil nitrogen and phosphorus were also rapidly turned over during the decomposition of glucose. The elimination of plateaus in the $\mathrm{CO}_{2}$ evolution curves when sulfur was added further supported the suggestion that the turnover rate of elements in this soil was nitrogen $>$ phosphorus $>$ other elements. Sulfur was the only element other than 
nitrogen and phosphorus which limited microbial activity in this soil, inasmuch as no response was obtained with the addition of any of the other mineral nutrients usually assumed to be essential for microorganisms. Apparently the levels of these elements were sufficient for maximum microbial activity.

In the previous paper it was suggested that the rate-limiting influence of inorganic elements might be used to control the activity and type of soil population. Although

Table 4. Sulfur content and carbon: sulfur ratio of some plant materials commonly added to soil

[From the data of MuLLER (1958)]

\begin{tabular}{l|c|c}
\hline \multicolumn{1}{c|}{ Plant material } & $\begin{array}{c}\text { Average S content } \\
\text { (mg/g) }\end{array}$ & $\mathrm{C} / \mathrm{S}^{\wedge}$ \\
\hline Alfalfa hay & $\mathbf{5}$ & 90 \\
Scybean hay & 2.8 & 161 \\
Oat straw & 2.4 & 187 \\
Wheat straw & 2.2 & 205 \\
Corn stover & 1.7 & 265 \\
Rye straw & 1.2 & 374
\end{tabular}

1 Carbon content of plant material was assumed to be $45 \%$. the rate of organic matter decomposition may possibly be controlled by manipulation of the $\mathrm{C} / \mathrm{N}$ or $\mathrm{C} / \mathrm{P}$ ratios, it is doubtful if the same could be accomplished with the $\mathrm{C} / \mathrm{S}$ ratio. The sulfur contents of some plant materials commonly added to soil are presented in Table4. The C/S ratios of these materials are substantially narrower than the ratio necessary for maximum rates of glucose oxidation. Inasmuch as this and other studies (FREDERICK et al. 1957;

STARKEY 1950; STEINBERg 1941) have shown that most organic forms of sulfur are as available as inorganic sulfur, and the work of JORDAN and BARKER (1959) has indicated that the sulfur contained in green manures is rapidly mineralized, this element should not be limiting in the decomposition of crop residues under natural conditions.

The minimum level of sulfur for normal plant growth ranges from 0.3 to $1 \mathrm{mg} / 100 \mathrm{~g}$ soil according to JORDAN and co-workers (1958) and LrTTLE (1958). This soil with a sulfur content of $0.38 \mathrm{mg} / 100 \mathrm{~g}$ was, therefore, undoubtedly sulfur-deficient. Nevertheless, neither the barley nor alfalfa crops that were grown on it prior to sampling, nor the potato crops grown subsequent to sampling, exhibited visible sulfur deficiency. Plants absorb $\mathrm{SO}_{2}$ directly from the atmosphere and may satisfy part of their sulfur requirement from this source (FrIEd 1948, SETTERSTRom 1952, Thomas and Hendricks 1943). The fact that the plants did not exhibit a sulfur deficiency, even though the sulfur level in the soil was too low for maximum microbial activity, suggests that perhaps it is not sufficient to approach soil fertility only in terms of crop response. It may be necessary to fertilize with specific elements solely to satisfy the mineral requirements of the soil microflora. In studies in which highly carbonaceous materials, such as sugars, are added to soil for the purpose of increasing microbial activity, the requirement of the soil microflora 
for sulfur, and for other elements, should be as well defined as the requirements for nitrogen and phosphorus. In our investigations of factors which limit microbial activity in soil, the use of sulfur has provided a simple mechanism whereby the activity and the ecology in the soil can be controlled.

\section{Summary}

The only nutrient element other than nitrogen and phosphorus which limited microbial activity in a sandy soil was sulfur. The addition of extremely small quantities of $\mathrm{MgSO}_{4}$, ranging from 0.32 to $1.6 \mathrm{mg}$ sulfur $/ 100 \mathrm{~g}$ soil, markedly increased the rate of oxidation of glucose. The optimum concentration of sulfur was correlated with the levels of glucose added, and a C/S ratio of 900 or less was required for maximum respiration. A number of compounds containing sulfur at different oxidation stages and in various structural configurations readily satisfied the sulfur requirement, indicating that the response was to sulfur as a nutrient and not to sulfate as an electron acceptor. Thiourea and elemental sulfur were utilized only slightly. The differential utilization of the various sulfur-containing compounds and the implications of sulfur as a limiting factor of microbial activities in soil were discussed.

Acknowledgments. The authors express their appreciation to Dr. A.S. Sussuan, Department of Botany, the University of Michigan, for helpful suggestions and criticisms during the course of these studies.

\section{References}

Frederick, L. R., R. L. Starkey and W. Segal: Decomposability of some organic sulfur compounds in soil. Soil Sci. Soc. Amer. Proc. 21, 287-292 (1957).

Freney, J. R.: Aerobic transformation of cysteine to sulphate in soil. Nature (Lond.) 182, 1318-1319 (1958).

FrIED, M. I.: The absorption of sulfur dioxide by plants as shown by the use of radioactive sulfur. Soil Sci. Soc. Amer. Proc. 13, 135-138 (1948).

Fuller, W. H., A. B. CASTER and W. T. MCGeorge: Behavior of nitrogenous fertilizers in alkaline calcareous soils: I. Nitrifying characteristics of some organic compounds under controlled conditions. Arizona Agric. exp. Sta. Tech. Bull. 120, 451-466 (1950).

GleEN, H., and J. H. QUASTEL: Sulphur metabolism in soil. Appl. Microbiol. 1, $70-77(1953)$.

GuttTonnead, G., and J. KeILIING: L'évolution et la solubilisation du soufre élémentaire dans la terre arable. Ann. Agron. N. S. 2, 690-725 (1932). (Original not seen).

Hesse, P. R.: Sulphur and nitrogen changes in forest soils of East Africa. Plant and Soil $9,86-96$ (1957).

Jordan, H. V., and O. G.BAREER: Sulfur studies in north Tdaho soils using radiosulfur. Soil Sci. 88, 1-6 (1959).

JoRDAN, H. V., and C. E. BARDSLeY: Response of crops to sulfur on Southeastern soils. Soil Sci. Soc. Amer, Proc. 22, 254-256 (1958).

Jordan, H. V., and L. E. Ensmenger: The role of sulfur in soil fertility. Advanc. Agron. 10, 408-432 (1958). 
LEEs, H.: The biochemistry of the nitrifying organisms: I. The ammonia-oxidizing systems of Nitrosomonas. Biochem. J. 52, 134-139 (1952).

LITTLE, R.C.: Sulphur in soils: III. A study of the readily soluble sulphate content and of the total sulphur content of soil. J. Sci. Food Agric. 9, 273-281 (1958).

MILLER, D. F. (compiler): Composition of cereal grains and forages. Agricultural Board, Nat'l. Acad. Sei. and Nat'l. Res. Council (1958).

QUASTEL, J. H., and P. G. ScholEFTELD: Biochemistry of nitrification in soil. Bact. Rev. 15, 1-53 (1951).

iSetTerstrom, C.: Effects of sulfur dioxide on plants and animals. Ind. Eng. Chem., Ind. Ed. 32, 473-479 (1952).

Staht, W. H., B. MoQue, G. R. Mandels and R. G. H. Siv: Studies on the microbiological degradation of wool. I. Sulfur metabolism. Arch. Biochem. 20, $422-432$ (1949).

STARKEY, R. L.: Relations of microorganisms to transformations of sulfur in soils. Soil Sci. 70, 55--67 (1950).

STARkeY, R. L.: Transformations of sulfur by microorganisms. Ind. Eng. Chem. 48, $1429-1437$ (1956).

Starkey, R. L., G. E. Jones and L. R. Frederick: Effects of medium agitation and wetting agents on oxidation of sulfur by Thiobacillus thiooxidans. J. gen. Microbiol. 15, 329-334 (1956).

Steinberg, R. A.: Sulfur and trace-element nutrition of Aspergillus niger. J. Agric. Res. 63, 109-127 (1941).

ISTOтzkY, G.: A simple method for the determination of the respiratory quotient of soils. Canad. J. Microbiol. 6, 439-452 (1960).

Stotzkx, G., and A. G. Norman: Factors limiting microbial activities in soil: I. The level of substrate, nitrogen and phosphorus. Arch. Mikrobiol. 40, 341 bis 369 (1961).

Stotzky, G., T. M. Ryan and J. L. Montensen: Apparatus for studying biochemical transformations in incubated soils. Soil Sci. Soc. Amer. Proc. 22, $270-271(1958)$.

Thomas, M. D., and R. H. Hewnotoks: Utilization of sulfate and sulfur dioxide for the sulfur nutrition of alfalfa. Plant Physiol. 18, 345-371 (1943).

VIshniac, W., and M. SANTER: The Thiobacilli. Bact. Rev. 21, 195--213 (1957).

VoGLER, K. G., and W.W. UMbReIT: The necessity for direct contact in sulfur oxidation by Thiobacillus thiooxidans. Soil Sei. 51, 331-337 (1941).

Waksman, S. A.: Soil Microbiology. New York: John Wiley and Sons, Inc. 1952.

WEST, P. M., and A. G. LOCHHEAD: Qualitative studies of soil microorganisms. IV. The rhizosphere in relation to the nutritive requirements of soil bacteria. Canad. J. Res. 18, 129-135 (1940).

Dr. G. StotzKY

Central Research Laboratories, United Fruit Company, Norwood, Mass. (U.S.A.) 